\title{
Acceptance and Decline of Pap Smear in a Tertiary Care Setup
}

\author{
Shazia Tazion", Maimoona Hafeez, Nishat Akram, Rukhsana Manzoor, Nazia Badar \\ Department of Gynaecology \& Obstetrics, Faculty of Sharif Medical \& Dental College, Lahore, Pakistan \\ Email address: \\ drtazion@yahoo.com (S. Tazion), maimoonahafeez@gmail.com (M. Hafeez), nishatakram0@gmail.com (N. Akram), \\ rukhsanaz@hotmail.com (R. Manzoor),drnaziabadar@yahoo.com (N. Badar) \\ ${ }^{*}$ Corresponding author
}

\section{To cite this article:}

Shazia Tazion, Maimoona Hafeez, Nishat Akram, Rukhsana Manzoor, Nazia Badar. Acceptance and Decline of Pap Smear in a Tertiary Care Setup. Journal of Gynecology and Obstetrics. Vol. 8, No. 1, 2020, pp. 20-23. doi: 10.11648/j.jgo.20200801.15

Received: December 2, 2019; Accepted: January 15, 2020; Published: February 4, 2020

\begin{abstract}
Cervical carcinoma is the second most common malignancy of genital tract. Risk factors include early age at first intercourse, smoking and multiple sexual partners. Cervical cancer can be prevented by Pap smear screening test. Pap smear is still an underutilized diagnostic modality in under developed countries. Provision and appropriate treatment should be offered in female. Objective of this study was to address the mindset of our females about pap smear screening and spreading awareness. This descriptive study was done in Obstetrics and Gynecology department of Sharif Medical City Hospital Lahore from January 2017 to January 2018 on 180 patients. Age, parity and duration of marriage were expressed as mean and frequency with percentages. Reasons of acceptance and decline were also expressed as frequency with percentage. The age range of the patient in present study was between 18-62 \pm 8.565 years. Regarding marital status, all the recruited females were married. Parity range was from $0-9 \pm 2.101$ with a mean parity of 3.03 . There were 129 females who accepted Pap smear. The most frequent reason for acceptance was recommendation by doctor in 93 (72\%) patients. Out of 180 patients, 51 patients were those who decline Pap smear. The reason of decline was fear of pain in 17 (33.3\%) patients, fear of a positive result and lack of knowledge. Cervical cancer is a deadly disease which affects the females in their early reproductive year. Screening should be offered in all reproductive females and it should be promoted through media campaigns. It is the responsibility of doctors as well to offer this screening test to all the female coming with or without gynecological complaints.
\end{abstract}

Keywords: Pap Smear, Cervical Carcinoma, Human Papilloma Virus, Risk Factors

\section{Introduction}

Cervical carcinoma is the second most common malignancy of genital tract. Cervical cancer is caused by human papilloma virus type 16 and 18 which is a sexually transmitted infection. Risk factors include early age at first intercourse, smoking and multiple sexual partners [1]. Throughout the world 493,000 new cases are reported annually and 274,000 death due to cervical carcinoma. In underdeveloped countries, $83 \%$ cases are reported of cervical carcinoma making an annual death rate of $15 \%$ [2]. In 2008, national cancer coalition found out that lack of effective screening programme is the main reason of high incidence of cervical cancer. In underdeveloped countries it is associated with maternal morbidity and mortality as well [3, 4]. Cervical cancer can be prevented by Pap smear screening test which is cheap, proficient and effective test in detection of cervical abnormalities. By spreading the knowledge of cervical cancer screening, in United States there is a $2 \%$ per year decline of death due to cervical cancer. United Kingdom had also observed a decline in cervical cancer due to wide implementation of cervical screening programme. In developed countries screening is offered at 25 years with a repeat test every 3 years till 49 years and then five yearly till 64 years. But underdeveloped countries are still lagging behind and we still receive a lot of patients who are at advanced stage of disease where radiotherapy is the only hope with least survival. There is a need to increase the acceptance of Pap smear screening in our country as well, which has a proven efficacy to reduce the incidence and death due to cervical carcinoma. In a study by Gustafsson et al, $90 \%$ reduction in the incidence of cervical cancer is seen 
by Pap smear screening [5]. The rate of screening by pap smear in underdeveloped countries is less than $10 \%[6,7]$.

Lack of knowledge, lack of provision of pap smear screening programme and lack of health care facilities are the main reasons of development of carcinoma of cervix in developing countries [8]. The sensitivity of pap smear is $50-75 \%$ and specificity is $98-99 \%$ [9]. HPV infection can affect $75 \%$ of women worldwide [10]. Preventive measures needs to be adopted which include having pap smear frequently, vaccination against HPV, quit smoking and adopting safe sex practices $[11,12]$.

Screening of cervical cancer has been advanced. New screening programme models are introduced. Visual inspection with acetic acid (VIA) and human pappilloma virus (HPV) DNA is the test which is commercially available in China and India since 2013. These tests are cheap and effective alternative to Pap smear in low resource countries. VIA has been selected by 24 countries as a national screening strategy. HPV-DNA testing has a higher sensitivity in the detection of high grade cervical lesions than Pap smear and VIA [13].

The objective of doing this study is that Pap smear is still an underutilized diagnostic modality in underdeveloped countries. We receive patients of cervical carcinoma at an advanced stage due to the lack of provision and awareness of Pap smear in our population. Cervical cancer can be detected at an early stage with the use of Pap smear and continuous follow-up of patients. Most patients are either not aware of it or don't want to get it done. So it's a need of time to spread awareness in our ladies about this disease and find out the reasons of acceptance and decline of this preventive diagnostic modality. By doing so, we can address the concerns of patients more appropriately and can use it more efficiently and effectively.

Rationale of study is that we need to address the mindset of our patients. Majority of our patients came from periphery for which the importance of this screening test is least. By doing this study we will find the reasons to address the perception and attitude of females. This will help us in increasing the acceptability of pap smear. Local studies are available but still there is need to do studies in different setups.

\section{Material and Method}

This descriptive study was done in obstetrics and gynecology department of Sharif Medical City Hospital Lahore from January 2017 to January 2018 on 180 patients. Ethical approval was taken from ethical committee of Sharif City Hospital. Patients were recruited from OPD by convenient sampling technique coming with gynecological or obstetrical problems. A survey Proforma was formed and all the data was entered on it by direct questioning by doctor. Sample size was calculated approximately 180 with confidence interval of $95 \%$ with acceptable difference of 0.05 and with assumed proportion of knowledge as $12.6 \%$. All the available data was entered on SPSS version 23. Age, parity and duration of marriage were expressed as mean and frequency with percentages. Reasons of acceptance and decline were also evaluated as frequency with percentage.

\section{Results}

The age range of the patient in present study was between $18-62 \pm 8.565$ years as shown in table 1 . Regarding marital status, all the recruited females were married with duration of marriage shown in table 2. Parity range from $0-9 \pm 2.101$ with a mean parity of 3.03 (table 3). Out of 180 patients, 51 patients were those who decline pap smear (table 4). Out of 180 patients, 129 patients accepted the pap smear (table 5). The most frequent reason for acceptance was recommendation by doctor in $93(72 \%)$ patients.

Table 1. Age in years $(n=180)$.

\begin{tabular}{lll}
\hline Age & Frequency & Percentage \\
\hline$<20$ years & 3 & $1.6 \%$ \\
$21-25$ years & 22 & $12.2 \%$ \\
26-30 years & 51 & $28.3 \%$ \\
$31-35$ years & 42 & $23.3 \%$ \\
$36-40$ years & 32 & $17.7 \%$ \\
$41-45$ years & 13 & $7.2 \%$ \\
$45-50$ years & 10 & $5.5 \%$ \\
$>50$ years & 7 & $3.8 \%$ \\
Total & 180 & $100 \%$ \\
\hline
\end{tabular}

Table 2. Duration of marriage $(n=180)$.

\begin{tabular}{lll}
\hline Married for & Frequency & Percentage \\
\hline 1-5years & 58 & $32.2 \%$ \\
6-10 years & 55 & $30.5 \%$ \\
11-15 years & 18 & $10 \%$ \\
16-20 years & 28 & $15.5 \%$ \\
21-25 years & 8 & $4.4 \%$ \\
26-30 years & 10 & $5.5 \%$ \\
$>30$ years & 3 & $1.6 \%$ \\
Total & 180 & $100 \%$ \\
\hline
\end{tabular}

Table 3. Parity $(n=180)$.

\begin{tabular}{lll}
\hline Parity & Frequency & Percentage \\
\hline Nulliparous & 23 & $12.8 \%$ \\
Para 1 & 20 & $11.1 \%$ \\
Para2-3 & 71 & $39.4 \%$ \\
Para 4-5 & 41 & $22.8 \%$ \\
$>5$ parity & 25 & $14 \%$ \\
Total & 180 & $100 \%$ \\
\hline
\end{tabular}

Table 4. Reasons of decline of cases of Pap smear $(n=51)$.

\begin{tabular}{lll}
\hline Reasons of decline & Frequency & Percentage \\
\hline Do not know about it before & 5 & $9.8 \%$ \\
Fear of pain & 17 & $33.3 \%$ \\
Fear of a positive result & 11 & $21.56 \%$ \\
Lack of awareness about cervical cancer & 1 & $1.96 \%$ \\
Lack of knowledge & 7 & $13.7 \%$ \\
Anxiety/ embarrassment & 2 & $3.92 \%$ \\
Financial cost & 7 & $13.7 \%$ \\
Others & 1 & $1.96 \%$ \\
Total & 51 & \\
\hline
\end{tabular}


Table 5. Reasons of acceptance of pap smear $(n=129)$.

\begin{tabular}{lll}
\hline Reasons of acceptance of pap smear & Frequency & Percentage \\
\hline Recommended by doctor & 93 & $72 \%$ \\
Screening test & 10 & $7.7 \%$ \\
Came to know by friend or relative & 8 & $6.2 \%$ \\
$\begin{array}{l}\text { Heard on TV/radio/social network } \\
\text { Performed previously and now on follow up }\end{array}$ & 18 & $13.95 \%$ \\
$\begin{array}{l}\text { Seen someone in family suffering from } \\
\text { disease }\end{array}$ & 0 & 0 \\
Others & 0 & 0 \\
Total & 129 & 0 \\
\hline
\end{tabular}

\section{Discussion}

Cervical cancer can be prevented by early detection of precancerous lesions and timely treatment. Developed countries like UK had adapted a nationwide screening programme. Underdeveloped countries like ours are still lagging behind in the implementation of these programmes at mass level. For this reason we receive patients at an advanced stage of disease, at that time the only cure is giving radiotherapy and palliative care. Moreover, Screening behaviors are also affected by the cultural and religious beliefs, barriers in communications, habits, customs and socioeconomic class as well.

The age range of the patient in present study was between 18-62 \pm 8.565 years which are comparable to a study performed in Cameroon [2].

Results of study shows that majority of females were married and residing in rural areas in a low socioeconomic class. These findings are comparable to a study performed in Brazil [12]. To our surprise, out of 180 patients who were offered screening, 129 (71\%) females accepted it despite coming from a rural background. These finding are comparable to a study performed in Nigeria where awareness of population was $74.6 \%$ [1]. While decline was noted in 51 $(28 \%)$ females. These findings contradict with the finding of a study done in Karachi where lack of awareness was found to be lack of information of health care provider about the disease [13].

This also highlight the importance of training of health care professionals in disseminating this information to their patients and offering pap smear in those patients who are coming with other complaints and addressing their fear as well.

Among the patients who accepted pap smear the most frequent reason was recommendation by a doctor, these finding are comparable to a study performed in China [14]. The other frequent reason was information through TV, radio and social networking which is in contrast to a study performed in Nigeria where it was found to be a most frequent source of information [1]. This reflects the importance of media contribution toward spreading awareness. None of the participants had a family member suffering from disease.

Decline was seen in 51 patients only and the most frequent reason encountered for decline was fear of pain, followed by fear of a positive result and lack of knowledge. These finding are comparable to a study performed in Canada $[15,16]$. People are not aware of sign and symptoms of disease and risk factors these findings are comparable to a study performed in Saudi Arabia [17, 18].

\section{Conclusion}

Cervical cancer is a deadly disease which affects the females in their early reproductive year. Detection of the disease by Pap smear of early dysplastic lesions and precancerous lesions is a option for all females. Screening should be offered in all reproductive females and it should be promoted through media campaigns. It is the responsibility of doctors as well to offer this screening test to all the female coming with or without gynecological complaints.

Based upon the results of the study following recommendations were made.

\section{Recommendations}

i. Mass screening at government level should be offered. Awareness campaigns through media, seminars and at social and religious forums needs to be done to spread awareness in our females.

ii. Training of trainers i.e. the health providers need to know the importance of offering this test which can reduce the burden of disease and early diagnosis of precancerous lesions can be done.

iii. Public sector hospitals are offering this test free of cost or at a negligible cost, private sector hospital cost it in varying range. To eliminate the barrier of financial burden the cost needs to be kept at a minimum.

iv. Most of the doctor don't know what to do if a test comes positive or even have difficulty in interpretation of results. Promotion of referral system and timely referral to a dedicated centre with colposcopic services should be done. Enhancing the skill of primary care Staff should be done to deal with such patients.

v. Risk factors for cervical cancer include early age at first intercourse, having multiple sexual partners and smoking. Spreading awareness about these risk factors is a beneficial step in reducing the burden of disease.

vi. Strengthening the system's capacity at tertiary care level for diagnostic imaging, cytology and histopathology. Provision of treatment equipment of precancerous lesions and cancer treatment should be done.

vii. At Government level a case registry should be maintained to establish the incidence of cervical cancer.

viii. Promotion of vaccination against HPV in all pre-pubertal girls and in those with high risk sexual behaviors should be offered. 
ix. Frequency of Pap smear should be according to our local protocol and systems needs to be established to provide this service to all out reach areas as well.

\section{Limitation and Strengths of Study}

Sample size of the study was small and it may not be a true representative of the whole population. Studies are needed at a larger scale with more sample size with multicentre involvement and randomized case control trials. This study, however give us overview about knowledge of cervical cancer in our females and highlight the need to do further studies.

\section{Ethical Approval}

Ethical approval was taken from hospital ethical committee.

\section{References}

[1] Ubajaka C, Ukegbu A, Ilikannu S, Ibeh C, Onyeonoro U, Ezeanyim A. Knowledge of cervical cancer and practice of pap smear testing among secondary school teachers in Nnewi north local government area of Anambra State, South Eastren Nigeria. Advances in sexual medicine. 2015; 5: 13-21.

[2] Ekane GEH, et al. Pap smear screening, the way forward for prevention of cervical cancer. A community based study in the Buea Health District, Cameroon. Open journal of obstet and gynecol. 2015; 5: 226-233.

[3] Cervical Cancer Screening: Cancer Care Ontario. n. d. [Available http://www.cancercare.on.ca/pcs/screening/cervscreenin g/; cited 9 February 2016.

[4] Pendrith C, Thind A, Zaric GS, Samra S. Cost of cervical cancer treatment: population-based estimates from Ontario. CurrOncol 2016; 23 (2): e109-15.

[5] L. Uche Chika, C. Ekeleme N, C. Iwuoha E, J. Awa M. Awareness and practice of Pap smear among female hospital workers in Abia state university teaching hospital Aba South East Nigeria. Int J tropical disease \& health. 2017; 28 (3): 1-8.

[6] Wardel J, Robb K, Vernon S, Walter J. Screening for prevention and early diagnosis of cancer. Am Psychol 2015; 70 (2): 119-33.
[7] Tota JE, Bentley J, Blake J, et al. Introduction of molecular HPV testing as a primary technology in cervical cancer screening: acting on evidence to change the current paradigm. Prev Med 2017; 98: 5-14.

[8] Ghebre R, Grover S, Xu MJ, Chuang LT, Simonds H. Cervical cancer control in HIV-infected women: past, present and future. Gynecol Oncol Rep 2017; 21: 101-8.

[9] Rani A, Singh K, Thapa S. Survey of awareness of Pap smear and cervical cancer vaccine among women at tertiary care centre in Eastern Uttar Pradesh India. Int J Reprod Contracept Obstet Gynecol. 2015; Apr: 4 (2): 439-441.

[10] Whop LJ, Cunningham J, Condon JR. How well is the National Cervical Screening Program performing for Indigenous Australian women? Why we don't really know and what we can and should do about it. Eur J Cancer Care 2014; 23: 716-20.

[11] NPS. NPD Medicine Wise. Special ed. NPS Radar; 2015 [Available at: http://www.nps.org.au/radar/articles/chnage-tothe-natio nal-cervical-screening-programm].

[12] Matsuo K, Mabuchi S, Okazawa M, Kawano M, Kurod H, Kamiura $\mathrm{S}$ et al. Clinical implication of surgically tested early stage cervical cancer with multiple high risk factors. Gynecol Oncol 2015; 26 (1): 3.

[13] Shama Razzaq, et al. knowledge and awareness regarding cervical cancer and uptake of pap smear among women in Karachi, Pakistan. EC Gynecology. 4.4 (2017): 154-161.

[14] Abulizi G, Abulimiti T, Li H, Abuduxikuer G, Mijiti P, Su-Qin Zhang et al. Knowledge of cervical cancer and Pap smear among Uyghur women from Xinjiang, China. BMC Women Health. 2018; 18: 21

[15] J. P. H. Wong, M. Vahabi, J. Miholjcic, V. Tan, M. Owino, A. T. W. Li et al. Knowledge of HPV/cervical cancer and acceptability of HPV self-sampling among women living with HIV: A scoping review. CurrOncol. 2018; 25 (1): 73-82.

[16] M. Vahabi, A, Lofters. HPV self-sampling: A promising approach to reduce cervical cancer screening disparities in Canada. Curr Oncol. 2018; 25: 13-18.

[17] Malibari SS. Knowledge about cervical cancer among womrn in Saudi Arabia. Egyptian Journel of Hospital Med. 2018; 70 (10): 1823-1825.

[18] Mulhim, NKA-O, Mohammed, Saad Morsi AM. Knowledge about cervical cancer early warning signs and symptoms, risk factors and vaccination among students at a medical school in Al-Ahsa, Kingdom of Saudi Arabia. Asian Pac J Cancer Prev. 2014; 15 (6): 2529-2532. 